\title{
Gender Projection Model: A New Motivational Approach of Women Under- representation in Organizations
}

\author{
Carrel Thomas ${ }^{1}$, Gabarrot Fabrice ${ }^{1}$, Dietz Joerg ${ }^{2}$, \& Salès-Wuillemin Édith ${ }^{1}$ \\ Laboratoire PSY-DREPI, EA 745, Université Bourgogne Franche-Comté ${ }^{2}$, HEC Lausanne, \\ University of Lausanne ${ }^{2}$ \\ Email: carrelthomas@gmail.com
}

Abstract

The purpose of the present paper is to introduce the Gender Projection Model. After a short review of the different accounts and theories on gender discrimination in the workplace, and of the three main phenomena: the glass ceiling, the backlash effect and the glass cliff, we present the gender projection model (GPM), a cognitive and motivational model for predicting the selection and self-selection of women in management positions. Our model posits gender projection, the assignment of typical gender characteristics to the position of manager, as a central mechanism accounting for the development of the manager prototype, both the (discriminatory) behavior and attitudes of personnel decision-makers (e.g., selection and/or evaluation of a male/female candidate) and the motivation and performance of (prospective) male and female managers. We believe this model will allow a better understanding of the construction of the manager prototype to explain the underrepresentation of women at the highest levels of the organizational hierarchy.

Key Words: Gender Projection Model, Gender Discrimination, Glass Ceiling, Glass Cliff, Backlash Effect 
While the representation of women in managerial positions has increased in recent decades, a gender imbalance persists in the salary levels awarded to men and women, as well as in the representation of women in the highest positions in the hierarchy of large organizations. For instance, in France, a woman is likely to earn $15.5 \%$ less than a man (Le Monde, 2019). This figure should be put into perspective: according to Korn Ferry (2016), in France, the wage gap between men and women is on average $17 \%$ but is reduced to $4 \%$ for equivalent positions. However, while the latter figure is much lower than those regularly cited, this study highlights that women have a more restricted access to more remunerative and prestigious positions than men (Le Monde, 2020). For instance, still in France, while $62 \%$ of civil service positions are held by women, they only represent $33 \%$ of management or executive positions (INSEE, 2016). Similarly, in the private sector, only one in five board seats (worldwide) is held by a woman (OECD, 2017).

Many reasons for such a gender imbalance have been invoked, such as women working less hour, having less work experience or ambitions, but also biases against women (see Ryan et al., 2007). The metaphor of the glass ceiling, used to depict the lack of career advancement of women in the absence of performance-based reasons, is descriptive of these biases. According to Morrison and Von Glinow (1990), this glass ceiling is "a barrier so subtle that it is transparent, yet so strong that it prevents women and minorities from moving up the management hierarchy" (p. 200).

In the present paper, we propose a psychological model for the under-representation of women in managerial roles. To be more precise, we address the research questions of why and when men's cognitive representations of managers ${ }^{1}$ - manager prototype - are more masculine than are those of women (e.g., Schein, 2001, 2007). Answering these questions is

\footnotetext{
${ }^{1} \mathrm{We}$ will use the term manager throughout this article to refer to people in a leadership position within an organization. This term, in the case of this article, also encompasses the terms director and leader.
} 
critical to understanding the under-representation of women because (a) most personnel decision-makers are men, in particular for upper-level positions, and (b) many psychological theories (e.g., Eagly \& Karau, 2002; Heilman, 1983, 1995) suggest that the perceived mismatch between female applicants and these managers prototypes often leads personnel decision-makers to prefer men over women.

Past theories (e.g., Eagly, 1987) have explained the "maleness" of cognitive representations of managers largely as a function of social realities: Manager prototypes are male because historically more men than women have been managers. Our gender projection model (GPM) explains why and when people's manager prototype is often more masculine than feminine. Specifically, we propose that people are more likely to project characteristics of their own gender group onto the manager prototype because such a position would provide a positive image to their ingroup, and that this prototype will serve as a comparison in personnel decision-making. As most personnel decision-makers are men, this gender projection process results in an overall more masculine than feminine manager prototype. Our model is also more fitted to explain why this manager prototype differs between men and women.

Moreover, our model helps identify several variables explaining when people are more likely to project characteristics of their gender group onto the prototype of the manager. Drawing on social identity theory, our model accounts for group or situational differences in gender projection by suggesting that people's projection of their gender group onto the manager prototype will depend on the ability of the latter to provide a positive image for their ingroup but will also be moderated by socio-structural variables, such as group status, stability and legitimacy of such status, or boundaries between gender groups. It also accounts for individual variability in the manager prototype by proposing a pivotal role of peoples' dual identification, both with their gender ingroup and with the manager position. The gender 
projection process will result in a more or less masculine manager prototype which will result in the differential evaluation and selection of male and female applicants for a manager position."

After a quick review of the literature, we will present our Gender Projection Model (GPM). In our view, the GPM makes several potential contributions to the understanding of gender phenomena in the workplace. Scientifically, our model allows for a more complete explanation of cognitive representations of managers by creating both output knowledge (e.g., explaining gender differences) and process knowledge (e.g., proposing variables that reinforce or suppress gender differences in manager prototypes). Finally, as a practical implication, our research provides an explanation for gender imbalances at the top levels of corporations despite overall increasing gender equality.

\section{Psychological Explanations of Gender Phenomena in Organizations}

\section{Glass Celling}

Traditionally, the social representation of a manager is that of a man. Managers are therefore described with masculine characteristics. Characteristics typically associated with either men or women have been categorized in two different dimensions: masculinity and femininity; competence and warmth; agentic and communal (see Abele, Ellemers, Fiske, Koch \& Yzerbyt, 2020, for a review; Koenig, Eagly, Mitchell \& Ristikari, 2011, for an explanation). While competence or agentic (i.e., assertive, confident, efficient) characteristics are commonly associated with men, warmth and communal (i.e., friendly, sociable, trustworthy) characteristics are often attributed to women. These associations will in turn characterize the activities of men and women. Fiske, Cuddy, Glick, and Xu (2002), using the Stereotype Content Model (SCM), explained that, in a given situation, the dominant group (e.g., men) will be associated with agentic characteristics while the minority group (e.g., 
women) will be associated with communal characteristics. Therefore, there is an adequation between men and managers (Schein 1973, 1975; see also Bongiorno, Bain, Ryan, Kroonberg \& Leach, 2021; Brenner, Tomkiewicz \& Schein, 1989; Deal \& Stevenson, 1998) and a mismatch between the characteristics of women and managers (see the lack-of-fit model, Heilman, 1983). These would be two of the main reasons for the glass ceiling phenomenon (Cook \& Glass, 2014).

These stereotype-based approaches have two main implications. First, because they are rooted in widely shared stereotypical representations within a society, these approaches imply that the cognitive representations of managers should be broadly similar between men and women. However, a number of research studies tend to show that women, while they still perceive the position as more masculine than feminine, possess a relatively less masculine perception of management positions compared to men (see Koenig et al., 2011; see also Atwater, Brett, Waldman, DiMare \& Hayden, 2004; Brenner et al., 1989; Eagly \& Karau, 2002; Schein, 2001, 2007), and increasingly so (Schein, 2007). Second, these approaches suggest that it would then be necessary for a woman to adopt traits or behaviors usually assigned to men in order to reach such management positions. However, when they display masculine traits such as competence or assertiveness, women face another obstacle that prevents them from reaching management positions, namely, the backlash effect (Rudman, 1998).

\section{Backlash Effect}

When women present themselves with characteristics that are prescribed for leadership (e.g., masculinity, agenticity, assertiveness, competence), they then face a new hurdle: the backlash effect (Rudman, 1998; Rudman \& Glick, 1999, 2001). Women who possess the necessary characteristics for a leadership position (i.e., agentic) and are perceived to be competent for the position would be perceived as competent but less likeable (Rudman \& 
Glick, 1999, 2001; Powers \& Zuroff, 1988), and will, nonetheless, be penalized (e.g., economically, through lack of cooperation, or negative evaluations; Rudman, Moss-Racusin, Glick \& Phelan., 2012; Rudman \& Phelan, 2008; Eagly, Makhijani \& Klonsky, 1992; Lyness \& Heilman, 2006). Such counter-stereotypical women indeed possess characteristics that fit with manager position, but are penalized because such characteristics are proscribed to women (Eagly \& Karau, 2002), They would not be employed (or promoted) to leadership positions because they fail to be sufficiently suited to the role of a woman (i.e., they suffer from a deficit of communality). While being hard to reconcile with stereotype-based approaches of gender discrimination, the backlash effect is not incompatible with role-based theories.

Eagly expresses this idea through her Social Role Theory (Eagly, Wood, \& Diekman, 2000; see also Wood \& Eagly, 2010, 2012, 2015) and Role Congruity Theory (Eagly \& Karau, 2002). According to role-based approaches, attitudes towards women managers are determined by normative beliefs and expectations about descriptive, prescriptive, and proscriptive behaviors and characteristics of men and women. Hence, by adopting the characteristics of managers, women will violate what is described and prescribed to them.

In sum, taken at face value, these stereotype-based and role-based accounts for glass ceiling and backlash effect suggest that women are facing a catch-22 situation: they either are perceived as being too and then will not be suitable nor chosen for a leadership position, or, in the opposite, they are perceived as too masculine, competent, or assertive but then would be perceived as overstepping their social roles and therefore will face a form of backlash (Burgess \& Borgida, 1999; Carli \& Eagly, 1999; Heilman, 2001; Rudman \& Glick, 1999, 2001). However, these role-based approaches do not describe motivations underlying the backlash effect (Rudman et al., 2012; Rudman \& Fairchild, 2004). 
A more recent explanation to the backlash effect is that women will not be recruited as manager not because of a lack of agency, nor because of a deficit of communality, not even because their abilities are incongruent with those of a manager, but because they threaten the gender hierarchy: a hypothesis labeled as the Status Incongruity Hypothesis (SIH; Rudman, Moss-Racusin, Phelan, \& Nauts. 2012).

The SIH suggests that women will experience backlash when they adopt behavior related to the high-status group (Nauts, 2015; Rudman et al., 2012). Rather than merely reflecting the relative position of men and women in our societies, the backlash would then be a tool for maintaining the social hierarchy (Jost, Banaji \& Nosek, 2004). In support to the SIH, Rudman \& Killianski (2000) showed that prejudice against female authority figures (e.g., bosses, professors, doctors, and police officers) was more positively associated with gender status than with gender stereotypes or roles. The backlash is thus proposed to be due to a status violation rather than a role violation.-Consequently, the more people are motivated to maintain the gender hierarchy, the more they will penalize agentic, assertive or dominant women (Rudman et al., 2012, Study 2). It is not atypicality that leads to backlash, but a threat to the status quo.

To summarize, three main social psychological explanations have been given for the under-representation of women in higher levels of the organizational hierarchy. It was first suggested that women could not attain positions of leadership because they did not seem to possess the necessary attributes to hold such positions. However, even when they appear to possess these attributes, women face a backlash effect: they would fail to reach these managerial positions, not because they do not possess the necessary attributes, but because possessing these attributes represents a violation of their social roles. Finally, the status incongruity hypothesis proposes that people do not penalize women only for contradicting 
their gender roles, but because they violate stereotypic expectancies that legitimize social hierarchies (Rudman et al., 2012).

Two more phenomena support status-based rather than stereotype-based or role-based explanations. The first is when women are placed in such managing positions as tokens to deflect accusations of prejudice and discrimination, or to signal for a more egalitarian organization (i.e., Tokenism; Kanter, 1977). The second situation appears when the company is facing periods of crisis or downturn, when the risk of failure is highest (i.e., Glass Cliff; Ryan \& Haslam, 2005).

\section{Tokenism}

Data from recent decades suggest that women are better represented at the highest levels of the organizational ladder (HCE, 2021), but still seem to be excluded from decisionmaking positions (Watkins, Simons \& Umphress, 2019). Tokenism refers to the practice of making a relatively small or trivial positive act towards a small number of members of a minority group (i.e., women), in order to give the appearance of fairness within a workforce. This perfunctory act allows the organization to appear unprejudiced, helps to deflect accusations of prejudice, and legitimize the resistance to engage in more meaningful positive policies.

When used as tokens, women may become managers, and thus violate their gender role, but do not experience a backlash effect. When women may reach a leadership position due to tokenism (Kanter, 1977) and, because the position does not offer them real executive power. Hence, they would not threaten the gender hierarchy (Yoder, 1991; Sidanius \& Pratto, 2001). Indeed, they have not been placed in this position due to their competence or merit, but to merely meet quotas, which discredits them, and, in turn, reinforces the hierarchy.

\section{The Glass Cliff}


There is another situation on which women may seemingly access high status positions within the organizational hierarchy, namely the Glass Cliff. Ryan and Haslam (2005) proposed the first description of the Glass Cliff phenomenon, which is defined as putting a woman - and more generally, a member of a minority group - in charge of a company when it faces difficulties (Cook \& Glass, 2014).

Literature on the Glass Cliff adds nuance to the explanations given for the glass ceiling phenomenon. When the company is successful, the typical glass ceiling situation, people, and especially men, attribute more masculine than feminine characteristics to an "ideal" manager. However, when the company is in crisis, people tend attribute relatively more feminine than masculine characteristics to an "ideal" manager (Ryan, Haslam, Hersby \& Bongiorno, 2011, Study 1 and 2). Thus, in times of crisis, it seems that the classic "think manager - think male" mental representation is replaced by another association: "think crisis-think female" (Ryan \& Haslam, 2007, 2008; Gartzia, Ryan, Balluerka \& Aritzeta, 2012; for a meta-analysis, see Morgenroth, Kirby, Ryan and Sudkämper, 2020).

One possible explanation of the Glass Cliff is that, when the company is in trouble, women are perceived to be more adaptable, more competent, and possessing a more effective leadership style in this situation. For instance, evidence from Ryan and colleagues (2011) show that people associated more stereotypically masculine attributes than feminine attributes to managers of a successful company, and less masculine than feminine attributes to a manager of an unsuccessful company (Study $1 \& 2$ ). However, the latter result seems to be explained more by a strong negative correlation between managers' descriptions and male attributes, than by a strong positive correlation between these descriptions and female attributes. So when a company faces difficulty, a woman will be perceived as a better fit for the manager position than a man, even more so when the manager is required to take on a relatively passive role (e.g., by enduring the crisis or being a scapegoat, Ryan et al, 2011, 
Study 3). However, this preference for feminine traits disappears when the manager is required to take on more prominent or active roles, such as serving as a spokesperson, or to improve the company's performance (Ryan et al., 2011, Study 3). Moreover, Bruckmüller and Branscombe (2010, Study 2) also showed that, in a context of crisis, instead of women being perceived as more suitable to manage a company in times of crisis, men are perceived as less adapted to lead in this situation and as less interpersonally skilled than women. Thus, another possible interpretation would be that women are favored in times of crisis, not because they seem to possess characteristics that are necessary to improve the company's situation, but because male decision-makers seek to protect their gender identity against managerial failure.

To sum up, sociological and psychological approaches to gender phenomena in the workplace emphasize the role played by decision-makers by focusing on social forces that shape employers' beliefs about desirable worker attributes (stereotypes or roles). Psychological theories (see Stockdale \& Nadler, 2012), mainly rely on the idea that the perception of leadership or managerial positions as predominantly masculine is quite consensual and can also be endorsed by women (Glick et al., 2000).

From our point of view, it seems that two types of explanations may coexist: an explanation in terms of stereotypes or role, primarily focused on cognitive factors, and an explanation in terms of status maintenance, thus highlighting underlying motivations. Although necessary, the cognitive factors and rational information processing underlying the stereotype-based or role-based approaches seem not to be sufficient to explain the sex typing of managerial positions. Similarly, the motivational explanation provided by the SIH does not explain why the manager prototype changes according to the company's situation. It therefore seems important to us to add a theoretical framework that bridges the cognitive and motivational explanations - i.e., to understand the motivations underlying the choice of a male or female manager as well as why the manager prototype may vary as a function of the 
situational and individual factors. As prestige, status and earnings are at stake, identity motives are likely to account for a significant part of gender discrimination in the workplace. Below, we argue that variability in prototypes can be explained by considering social identity motives. And it is the perception of the managers prototype (as more or less masculine / feminine) that will predict the evaluation and/or the selection of a male or a female candidate. Therefore, we develop a cognitive and motivational model of gender discrimination focusing on gender projection as an explaining mechanism of gender-discriminatory personal decisions, for managerial and leadership positions. We therefore believe it is important to put forward a model that is dynamic and adaptable to the company's cultural and temporal context. We believe that the Gender Projection Model will make it possible to respond to the criticisms we have previously formulated.

\section{The Gender Projection Model}

In the following, we develop a cognitive and motivational model of gender discrimination (see Figure 1). The GPM is deeply rooted into the social identity approach and focuses on the gender projection process as a mediator of gender-discriminatory personal decision. We first introduce the social identity approach, grounded in social identity and selfcategorization theories. In a second section, we will present the moderators of the GPM and we detail the consequences of gender projection in-gender-discriminatory outcomes.

\section{The Social Identity Approach}

As a general psychological theory of group processes and intergroup relation, the social identity approach (see Hogg \& Abrams, 1988; Hogg \& Terry, 2001; Abrams \& Hogg, 2004), based on Social Identity Theory (SIT; Tajfel \& Turner, 1986) and Self-Categorization Theory (SCT; Turner, Hogg, Oakes, Reicher \& Wetherell, 1987), is well suited to account for 
phenomena for which identities are at stake. Central to this approach is the notion of social self. According to SIT, individuals are motivated to maintain a positive self-image, and a substantial part of this self-image is derived from the groups that the individual belongs to. Therefore, individuals have a strong motivation to promote the image of their social group. One way to do this is through positive intergroup comparisons. In the hiring process, these intergroup comparisons are likely to result in a more positive evaluation of applicants who are similar to recruiters (i.e., ingroup members) than of those applicants who are different (i.e., outgroup members).

According to SCT, people can see themselves as members of variously inclusive social categories. For instance, a person can see herself as a unique individual (very exclusive) or as a human being (very inclusive), as well as a member of a social group at any intermediate level of inclusiveness on this identity continuum (Tajfel \& Turner, 1986). These categorizations are perceived to be mutually exclusive (or functionally antagonistic; see Postmes, Baray, Haslam, Morton \& Swab, 2006; for a discussion of personal and social identity dynamics). That is, at a particular point in time, people would see themselves as members of either a more inclusive group or a less inclusive group but not of both at the same time. What dictates the salience of one particular social identity is then the interaction between the perceiver's readiness to use this category and the salience of the category in a particular context (Turner, Reynolds, Haslam \& Veenstra, 2006). Turner and colleagues (1987) further proposed that (1) the more "inclusive" social categories provide the necessary background for comparisons between lower order groups (i.e., comparative fit), and (2) the comparison will occur on dimensions that are normative or that define the higher order category (i.e., normative fit). The valued standard or norm dictating the outcome of the comparison is embodied in the group prototype. The prototype can be thought of as the imaginary ideal group member who best represents this social category in a given context. 
Consequently, according to SCT, the evaluation of ingroup and outgroup members depends on their perceived similarity with the prototype of a relevant higher order category.

These processes have been shown to account for a large variety of group phenomena within organizational settings, such as ingroup liking and attraction, leadership, persuasiveness or social influence, and of course ingroup bias (e.g., Hains, Hogg \& Duck, 1997; Turner \& Haslam, 2001; van Knippenberg, 2000). For instance, the potential for a group member to emerge as a manager is related to his or her matching with the group prototype (see van Knippenberg \& Hogg, 2003). Similarly, intergroup relations in the organizational setting are likely to be conditioned by characteristics of the organization's prototype. Employees will then be evaluated by their similarities or differences with this prototype. It is important to note that the representations of social categories and their prototypes are socially construed and not objectively given (Wenzel, Mummendey \& Waldzus, 2007). Thus, they can comprise true as well as erroneous characteristics and can vary as a function of the specific perspective of the perceiver (e.g., Oakes, Haslam \& Turner, 1998). Furthermore, the content of these social categories can be represented in ways that serve the perceiver's goals (Reicher \& Hopkins, 2001), resulting in a biased perception of both groups as well as the comparative framework (i.e., the superordinate category). The assumed process for this biased perception of the higher order category is ingroup projection (Wenzel et al., 2007). Ingroup projection can be defined as a process (or set of processes) by which lower order ingroup members expect the higher order category to be similar to their ingroup. In other words, subordinate group members tend to project the prototype of their ingroup onto the superordinate category (Wenzel, Mummendey, Weber \& Waldzus, 2003). For example, French people might have a French-colored perception of Europeans, whereas Germans might have a perception of Europeans more similar to their German prototype than to the French one. A consequence of this ingroup projection process is that, under certain 
conditions, group members will perceive their ingroup to be more prototypical of the superordinate category than the comparison outgroup.

In the context of gender occupational disparities, and because gender is a «primary cultural frame » for coordinating behavior and organizing social relations (see Ridgeway, 2009), the process takes the form of gender projection. Gender projection is defined as the process by which male or female perceivers expect occupational categories to be similar to their gender group. The main consequence of this process is that applicants and employees will be evaluated as a function of their similarity and difference with a gender biased prototype of a manager, rather than an objective stereotype. The extent to which male and female perceivers will project their gender group characteristics onto an organization or to a position within the organization depends on its value. Gender projection allows for malleability in the construction of prototypes of each category (woman, man, and manager), which is not possible with the SCM (Fiske et al., 2002) and the RCT (Eagly \& Karau, 2002) by adapting each representation of these categories for each individual, regardless of the social norm in which the individual is placed. This malleability of the gender projection also allows to adapt to the different situations that a company may face (success, crisis) by modifying the prototypes of each category according to the situation. This will allow for a better understanding of why women face the glass ceiling and the glass cliff. Moreover, it should allow for a better understanding of the backlash effect: if the manager prototype is associated with the men prototype, a woman will experience the backlash. Similarly, a man whose behavior is associated with the woman's prototype will experience the backlash.

As noted earlier, according to SIT, individuals are motivated to acquire or preserve a positive self-image, and this self-image is in great part derived from the group to which they belong. Consequently, to the extent that an organization or a position within an organization is perceived to promote a positive identity, members of that organization might consider the 
prototypical member to be similar to their own (gender) group, and thus evaluate the other employees with regards to the standards defining their own ingroup. Hence, a male recruiter, for example, may evaluate male and female applicants against his male-colored prototype of organizational members. Following this reasoning, it is plausible that the more central, important, or valuable a role (e.g., members of top management versus frontline employees) is within the organization, the more likely ingroup projection will occur and result in a disadvantage for a particular outgroup. As we said, gender projection allows categorization to be malleable. In other words, our model implies that if a position is prestigious and confers prestige, power, etc., whether the position is described as agentic or communal, the result of the projection will be the same: individuals will associate the position with the characteristics of their group. In other words, a man could very well be opportunistic and associate his gender group with a position with feminine characteristics, communal if the position requires such characteristics and confers prestige. Associating one's gender group with the leadership position can then be seen as a means of creating a positive identity. But if the position is in a difficult position (i.e., when the company is in crisis) this motivation for men to associate themselves with the position should diminish and they should prefer to see a woman reach the leadership position. Indeed, putting a woman in such a position allows them to defend their identity by protecting themselves from a complicated situation with a high risk of failure, while at the same time putting a member of a competing group (a woman) in difficulty. If the woman fails to avoid bankruptcy for the business, men may say that they (women) are not suitable for this type of position (Ryan \& Haslam, 2007, 2008; Ryan, Haslam \& Postmes, 2007). In addition, women will tend to view these complicated management positions as a career opportunity (Fitzsimons, Callan \& Paulsen, 2014). In the following, we will describe our Gender Projection Model using 6 basics principles from which more specific assumptions or hypotheses can be derived. The model is presented in Figure 1. 
--- Insert Figure 1 around here ---

\section{Gender Projection and the Glass Ceiling}

Our key argument is that perceivers' (e.g., personal decision-makers) manager prototype is affected by their motivation to attain or maintain a positive gender identity. Through the projection of gender group characteristics onto the superordinate category (e.g., manager), evaluators consider the characteristics that are originally specific to their gender group prototype as normative for the ideal manager prototype. As a result, to the extent that most decision-makers for the appointment of managers are likely to be male, the gender projection process is likely to account for both the candidates and the recruiters' determinants of the so-called glass ceiling.

Principle 1: Perceiver's gender will affect their mental representation of the typical manager position in such a way that the projection of masculine or feminine characteristics onto the manager position will depend on their gender.

Principle 1 suggests a direct effect of gender identity on the prototype manager. Gender is one of the primary cultural frames for organizing social relation (Ridgeway, 2009) and we can assume it will be the same in organizational work (Ellemers, Rink, Derks \& Ryan, 2012). So, gender projection is likely to influence recruitment, evaluation, and self-selection processes. It implies that an actual or potential employee will be evaluated to some extent as a function of his or her similarities and differences with a biased prototype of the position and/or the organization. In recruitment settings, the gender projection process implies that this 
prototype is likely to be biased in the direction of the recruiter's gender group. Consequently, applicants are not evaluated only as a function of their qualifications and background, but also as a function of their similarities and differences with the recruiter's ingroup, resulting in discrimination. Specifically, a male recruiter is likely more to expect a manager to possess more masculine than feminine characteristics than a female recruiter would. We should then expect a gender difference in the attribution of male and female traits to the manager stereotype. As we highlighted above, evidence of such a gender effect have already been found in the literature. Women attribute more feminine traits to the manager stereotype than men do (Dodge et al., 1995; Schein, 2001; Schein et al., 1989; see also Eagly \& Karau, 2002).

However, it is important to note that one should not expect male and female recruiters to project their respective ingroup in a similar extent. The gender projection process is likely to vary in intensity as a function of individual differences (i.e., identification with the superordinate or the subordinate group), and the characteristics of the superordinate category (i.e., the ability of the organization or the position to provide the ingroup with a positive social identity), but also characteristics of the gender group. Gender projection is likely to be constrained by the characteristics of the gender group, leading to differential attributions of gender specific traits as a function of group status within the organization (see Perry, 1994, Perry et al., 1994). For example, the reality is that women are under-represented among toplevel managers. Hence, women likely attribute fewer feminine traits to the superordinate category of top-level managers than they would if men and women were equally represented in executive suites. However, the amount of feminine traits women attribute to managers is likely to be higher than the number of feminine traits attributed by men. Consequently, even if it can be expected that both men and women recruiter will project their ingroup onto the manager stereotype, for reasons detailed below, such a projection is not likely to be symmetrical. Studies by Waldzus et al. (2004) give some support to the latter principle. East 
and West German participants were asked which of the East Germans and West Germans (subordinate category) are more prototypical of Germans in general (superordinate category). The authors showed that both East and West Germans agree that West Germans are more prototypical of Germans in general. Nevertheless, these two subgroups do not agree on how much more prototypical West Germans are: East Germans perceive less prototypicality of West Germans on the superordinate category than West Germans perceive themselves to be.

Similarly, Ryan et al. (2011, Study 1) showed that male participants tended to see a manager (of a successful company) as being similar to men but not to women. Female participants, however, tended to see managers to be similar to both men and women, but the association was slightly stronger among male traits than among female traits. This leads us to our first two/three assumptions.

Assumption 1.1: Both men and women will project more masculine (relative to feminine) traits onto the manager prototype.

Assumption 1.2: Men will project more masculine traits (and/or less feminine traits) onto the manager prototype than women.

Assumption 1.3: The difference between masculine and feminine traits projected onto the manager prototype will be larger for men than for women.

Principle 1 supposes that both male and female perceivers value to have their gender group represented in managerial or leadership groups. This supposition is generally plausible because membership or representation in groups of which one is or would like to be a member tends to be positively evaluated, in particular the more inclusive (i.e., superordinate) these 
groups are (Turner et al., 1987). In fact, managerial groups enjoy higher status in corporations than do non-managerial groups (e.g., Magee \& Galinsky, 2008). Yet there are variations in the status of managerial groups, for example, due to their relative rank within the organization. Consistent with SIT, according to which individuals are motivated to acquire or preserve a positive self-image, the extent to which individuals project characteristics of their gender onto their manager prototypes should decrease the less membership in the managerial or leadership groups can fulfill this motivation. The degree of gender projection and its consequences are hence conditional upon the status of the superordinate group (i.e., the organization as a whole or the position within the organization).

\section{Representation of the organization / position and the Glass Cliff Phenomenon}

The relation between the status of the organization and gender projection is relatively obvious with regard to SIT. SIT states that individuals are motivated to acquire or preserve a positive self-image by means of their social identity. Consequences of gender projection in terms of self-esteem and self-evaluation are thus conditional to features of the superordinate category such as its status, prestige or value. A high prestige organization or position within the organization is more likely to induce ingroup projection than a low prestige organization/position. As a result, high prestige or status or positively evaluated superordinate groups are more likely to induce gender projection than low prestige or status or negatively evaluated superordinate groups. Under certain conditions, an individual can alternately achieve a positive ingroup identity through the attribution of prototypical outgroup characteristics to a low prestige or status superordinate category. Such a process would result in the confinement of outgroup members to lower prestige or status categories. 
Principle 2: The extent to which membership or representation in managerial groups can enhance the gender social identity of perceivers influences the degree to which individuals project masculine and feminine characteristics onto manager prototypes.

Studies by Wenzel et al. (2003) give some support to the latter principle. German participants were asked to think and write a short essay about the positive (vs. negative) aspects of Europe. In a second stage, they were asked to rate Germans (ingroup) and Poles (outgroup) and to indicate their level of identification with the ingroup. The dependent variables were relative ingroup prototypicality (i.e., the difference between evaluation of the ingroup as being prototypical of the superordinate group, and evaluation of the outgroup to be so) and group evaluations. As suggested, the results showed that, when a positive evaluation of Europe was activated, ingroup identification was positively related to relative prototypicality, and relative ingroup prototypicality was related to negative outgroup evaluations. Conversely, when a negative evaluation of Europe was activated, ingroup identification was negatively related to relative ingroup prototypicality and relative ingroup prototypicality was related to positive outgroup evaluations. These results highlight that, when the superordinate category is positively evaluated, ingroup members perceived their ingroup to be more prototypical of the superordinate category, inducing negative evaluation of the outgroup. In the opposite, when the superordinate category is negatively evaluated, ingroup members engaged in the opposite of ingroup projection, that is, ingroup distancing.

In the organizational setting, this principle translates into the assumption that an unsuccessful organization will be less likely induce gender projection from its member than a successful one. This assumption explains why, despite an increased representation in the executive suites of numerous companies, women remain relatively scarce in higher-ranking companies (e.g., Fortune 500), except when the company is in trouble (Ryan \& Haslam, 
2005). Research on the Glass Cliff phenomenon (see Ryan et al., 2016), however, raises several questions. First, theoretically, this research suggests that a woman will be perceived as more suitable than a man for a managerial position in a failing company. This implies that such a position will be associated with more feminine traits than masculine traits (Ryan et al., 2011). However, empirical data collected to date seem to show that, in some cases, participants do not attribute more feminine traits to the manager in a failing company, but merely fewer masculine traits (Bruckmüller \& Branscombe, 2010; Ryan et al., 2011, Study 1). This latter observation seems to be consistent with our approach, however, future empirical research will test whether the expected lower gender projection is explained more by a lower projection of male traits or more female traits. This leads to the following assumptions:

Assumption 2.1: Men will project less masculine traits (and/or more feminine traits), onto the manager position within an unsuccessful organization, compared to a successful organization.

Second, this research on the glass cliff also raises questions about the assumptions that can be made for women. On the one hand, one might assume that women act similarly to men, and project fewer feminine characteristics (and/or more masculine characteristics) onto the prototype manager in a failing firm, as a way to protect their social identity. However, it is also possible to think that women see this type of position, regardless of the risk, as an opportunity to break the glass ceiling, and join a higher status group. 
Assumption 2.2: Women will project less masculine traits (and/or more feminine traits), onto the manager position within an unsuccessful organization, compared to a successful organization.

As noted above, the specificity of organizational context allows to hypothesize a difference in gender projection not only as a function of the features of the organization, but also as a function of the position occupied within this organization. Following this idea, we can derive the notion that a particular position within an organization needs to be particularly valued to induce gender projection.

Assumption 2.3: Men will project less masculine traits (and/or more feminine traits) onto a negatively valued position, compared to a positively valued position, within the organization.

The latter assumption leads to the hypothesis that male managers are likely to discriminate towards women in a greater extent as a function of the importance of the applied position within the organization. As a vast majority of decision makers in the organization are men, this assumption also explains why despite an increase representation in the labor market, women are in majority still confined to lower status position within the organization (see Catalyst, 2010).

This assumption also allows to account for the overrepresentation of male managers even in typically female dominated domains of activity (i.e., glass escalator, Williams, 1992). For instance, in Canada, in 2005, whereas men represented only $36 \%$ of the educational 
personnel in primary and secondary schools, they represented $53 \%$ of the principals of these same schools (Cattonar, 2007). Similarly, in the U.S., women represent an overall $75.6 \%$ of teachers; only $51 \%$ of principals are women. This rate drops to $28.5 \%$ when focusing on secondary school level (whereas women represent $59.3 \%$ of teachers at this level (Coopersmith, 2009). As a manager position is positively valued, even if the company's domain is predominantly feminine (like nursing or school teaching), and as men remain the decision-makers, even in these domains, one can assume that men will be favored over women for managerial positions.

Finally, as noted above, it reciprocally accounts for the observation that women are more likely to be appointed to a managerial position after a period of poor company performance or to more precarious manager positions, a phenomenon known as the glass cliff (Ryan \& Haslam, 2005; see above). The notion of glass cliff is not limited to leadership positions in poorly performing companies but extends to difficult management positions within the organization. Despite the relative precariousness of such position, women may see it as an opportunity to gain a foothold in the higher status group, and may consequently project more female characteristics (and/or fewer male characteristics) onto a such a position as a means of attaining a more valued position.

Assumption 2.4: Women will project less masculine traits (and/or more feminine traits) onto a negatively valued position, compared to a positively valued position, within the organization.

At first sight, this last proposal may seem contradictory with an approach based on the idea that social identity, and in particular gender projection, serves a primary function of in- 
group favoritism. One could argue that male decision-makers should object to the recruitment of female managers for these precarious positions, if they can be perceived as a gateway to the higher status group. However, the main characteristic of such positions is that they often are associated with a lack of support or acknowledgment and respect from (male) colleagues and superiors, as well as inadequate information (Ryan et al., 2007), thus reinforcing the existing status quo.

Moreover, this proposal invites us to question the role of socio-structural variables (i.e., perception of permeability, stability and legitimacy of intergroup relations) on gender projection. Thus, a managerial position, a priori of high status, whatever the level of risk attached to it, could be perceived as a form of permeability allowing women to aim for such a position $^{2}$.

\section{Socio structural variables: Status, permeability of group boundaries, and} stability/legitimacy of status asymmetry.

Having discussed the impact of a self-image enhancing value of the superordinate group's status, we now elaborate on the influence of features of the subordinate groups (e.g. women and men) on the process of gender projection. Drawing on SIT, we can propose a second class of variables likely to influence the intensity of gender projection: the representation of the subordinate gender groups, and of their relations within the organization. Tajfel and Turner (1986) specified that cognitive, motivational, and socio-structural factors interact to predict group members' responses to status hierarchies. They particularly proposed that the status hierarchy (i.e., belonging to a high status or a low status group), the status stability and legitimacy (i.e., the extent to which high and low status group members are willing to accept the status hierarchy, or question it to attain an alternative position) and the 
permeability of group boundaries (i.e., the extent to which an individual group member can leave their ingroup to join another, higher status, group), are likely to condition the willingness of an individual to challenge the status quo in order to obtain or maintain a positive self-image (see Bettencourt, Dorr, Charlton \& Hume, 2001). We believe that these socio-structural variables will also influence the extent to which an individual will project his subordinate gender group onto the organization or onto a specific position within the organization, accounting for the gender asymmetry in gender projection we described earlier.

Principle 3: The extent to which individuals will project characteristics of their gender group onto a superordinate category depends on their perceptions of the subordinate groups and their relations in terms of status, status legitimacy, stability, and permeability of group boundaries.

An abundance of research has shown that men enjoy higher material and social status than do women (for a review, see Sidanius \& Pratto, 2001). The higher status of men has been consistent across time and cultures. Despite differences in their actual status, individuals vary in the extent to which they view this difference as legitimate (e.g., Pratto, Sidanius, Stallworth, \& Malle, 1994). Consistent with Tajfel and Turner's (1986) formulation of social identity theory, the perceived legitimacy of the status that groups enjoy affects whether and how individuals maintain a positive self-image. Specifically, men as members of high-status groups who believe that their higher status is legitimate (e.g., because men supposedly work harder) are expected to be motivated to reinforce the status quo. Otherwise, an inconsistency between their belief in the legitimacy of their status and their behaviors would arise. This 
reasoning leads to the following assumptions about the projection of distinctive gender characteristics:

Assumption 3.1: The more both men and women perceive the difference in status between gender groups as legitimate, the more they will project masculine traits (and/or less feminine traits) onto the manager prototype.

Individuals do not only vary to what extent they view the current gender status as legitimate, but also to what extent they perceive the gender status as stable. It is important to acknowledge that stability does not refer to the biological stability of gender status. Instead, as we examine gender as a subordinate group in the context of the superordinate groups of managers and managers in organizations, stability of gender differences, as the earlier discussed notion of comparative fit in SCT implies, refers to stability of these differences in the context of managerial and leadership groups. Thus, for example, men may perceive instability in gender status in an organization that has had a significant influx of female managers in recent years. Furthermore, individuals also vary in the extent to which they perceive gender boundaries in organizations as permeable. Again, based on SCT, perceived permeability of gender differences does not refer to biological permeability, but the extent to which women have opportunities to "permeate" from lower organizational ranks to higher ones that historically have been reserved for men. For example, women may perceive that gender boundaries in organizations are permeable, yet stable, when they have observed that only a few women have ascended to the top. Perceptions of both stability of gender status and permeability of gender boundaries have motivational implications for women and men, as they imply threats and opportunities for enhancing the value of one's self-image through 
gender identity. If men believe that their higher status has an unstable foundation or that women increasingly rise to the organizational top (i.e., perceived permeability is high), men see the value of their gender identity as threatened and are expected to react by constructing particularly masculine manager prototypes. This reasoning leads the following assumptions:

Assumption 3.2: The less men perceive the difference in status between gender groups as stable, the more masculine traits (and/or less feminine traits) they will project onto the manager prototype.

Assumption 3.3: The more men perceive boundaries in organizations as permeable, the more masculine traits (and/or less feminine traits) they will project onto the manager prototype.

For women, we expect an asymmetrical effect. If women perceive that the existing gender status in organizations is unstable and that they can move up in the organizational hierarchy, they will infer opportunities for improving the status of their gender group. Hence, we formally postulate:

Assumption 3.4: The less women perceive the lower status of women relative to men as stable, the less masculine traits (and/or more feminine traits) they will project onto the manager prototype. 
Assumption 3.5: The more women perceive gender boundaries in organizations as permeable, the less masculine traits (and/or more feminine traits) they will project onto the manager prototype.

In addition to the self-image enhancing value of managerial and leadership groups and perceptions about gender groups (i.e., legitimacy, stability, and permeability), the extent to which perceivers identify with their gender group and managerial and leadership groups affects the projection of gender characteristics onto manager prototypes.

\section{Dual identification}

As noted above, a straightforward determinant of ingroup projection is the extent to which group members identify with the different groups at stake (i.e., their subordinate ingroup, as well as the superordinate category). While men and women likely recognize their membership in gender categories, there is variation in the extent to which they consider this category membership to be a central or important part of their self-image. This variation is captured by a person's gender identification (e.g., Luhtanen \& Crocker, 1992) or commitment to their gender group (Ellemers, Spears, \& Doosje, 2002), such that greater identification means a greater importance of the gender identity for one's self-image.

Similarly, individuals likely differ in the extent to which membership or representation in managerial and leadership groups is important to their self-image. A key implication of individual differences in identification with a group is that individuals who value a group membership as a central source of identity have a stronger motivation to maintain a positive image of that identity than do individuals who are less identified with that group. Thus, because membership or representation in managerial or leadership groups generally has a 
positive value for the self-image, we can expect that the more individuals identify with their gender, the more they will project masculine characteristics onto manager prototypes, as doing so improves the relative status of their gender group. Formally:

Principle 4: The extent to which one will project characteristics of their gender group onto an organization / position within an organization is determined by his or her identification with both their gender group and the organization/position within the organization.

On the one hand, the more an individual is identified with his lower level ingroup, the more he is likely to project features of this ingroup onto the superordinate category (Ellemers, Spears, \& Doosje, 2002; Wenzel et al., 2007). As we noted above, identification is likely to determine whether one will choose between an individual and a collective strategy to enhance his or her identity. Identification will also determine reaction to challenges to the status quo. Identification has been shown to moderate reactions to different kind of identity threat (Falomir-Pichastor, Gabarrot \& Mugny, 2009 a, b; Gabarrot, Falomir-Pichastor \& Mugny, 2009; see Ellemers et al., 2002 or Branscombe et al., 1999, for reviews). On the other hand, an individual also has to identify with the superordinate category to induce ingroup projection and for it to become a comparison standard. Thus, the IPM suggests that dual identification is necessary to promote ingroup projection and lead to, under certain conditions, to ingroup favoritism. Illustrating the role of identification, Wenzel, and colleagues (2003, Study 1) showed that students who identified strongly with their ingroup (business administration students or psychology students) and to the superordinate category (students) showed higher levels of relative ingroup prototypicality than those who were less identified. 
Assumption 4.1: The more men are identified with their gender group, the more masculine traits (and/or less feminine traits) they will project onto the manager prototype.

Assumption 4.2: The more women are identified with their gender group, the less masculine traits (and/or more feminine traits) they will project onto the manager prototype.

Assumption 4.3: The more men are identified with the organization/position, the more masculine traits (and/or less feminine traits) they will project onto the manager prototype.

Assumption 4.4: The more women are identified with the organization/position, the less masculine traits (and/or more feminine traits) they will project onto the manager prototype.

Furthermore, we propose that this effect is stronger for individuals who are additionally more strongly identified with managerial or leadership groups. In this case, the superordinate group of managers is particularly relevant for the self and, hence, more likely to serve as the comparative standard for gender group comparisons (Wenzel et al., 2007).

Assumption 4.5: The more men are identified with both their gender group and the organization/position, the more masculine traits (and/or less feminine traits) they will project onto the manager prototype. 
Assumption 4.6: The more women are identified with both their gender group and the organization/position, the less masculine traits (and/or more feminine traits) they will project onto the manager prototype.

This assumption is quite contradictory with the idea that dual identification will benefit to positive intergroup relations (see, for instance, Gaertner \& Dovidio, 2000). Dual identification is argued to allow for recategorizing the outgroup as a part of a common identity, without undermining the subgroup identity. In this framework, identification with the common identity implies a certain amount of similarity at the superordinate level (i.e., the subordinate ingroup and outgroup are perceived to be of comparable value), while subgroup identification allows for the necessary amount of distinctiveness at the subordinate level. On the opposite, the GPM suggests that the superordinate identity constitutes a comparison standard that makes inter-subgroup distinctiveness or threat a legitimate cause of discrimination (see Wenzel et al., 2007, for a similar argument). Consequently, we argue that perceptions of intergroup threat within the organization are likely to determine prejudice and discrimination as a function of gender projection.

\section{Consequences of gender projection}

The purpose of the present paper is to answer the questions of why and when people, and especially men, may possess a more masculine than feminine representation of the manager. To answer the "why" question, our model proposes that people may tend to project characteristics of their own gender group onto their cognitive prototype of a manager because such projection helps them achieving or maintaining a positive social—gender-based— identity. To answer the "when" question, we proposed a series of variables likely to increase 
or decrease the process of gender projection, such as the success or failure of the organization, the relative status of the manager position, but also socio-structural beliefs and identification with both the gender and the manager groups. Now it remains to us to answer the "what" question: what are the consequences of gender projection?

Literature shows that people's gender does not directly predict the selection or the evaluation of a candidate for a leadership position (Rudman \& Phelan, 2008; Rudman et al., 2012; Haslam \& Ryan, 2008; Ashby, Ryan \& Haslam, 2007; Morgenroth et al., 2020). It is not gender per se that accounts for people's evaluation or the selection of a candidate, but it is their representation of the manager prototype. As stated above, this representation might be colored or constrained by beliefs regarding the social structure within a given society. Gender projection is thus expected to account for the evaluation of a candidate for the managerial position. As we have suggested several times, the key principle of our model is that people (e.g., personnel decision makers) construct a manager prototype that is affected by their motivation to access or possess a positive gender identity. Through projecting characteristics of gender groups onto the prototype of the superordinate group (e.g., top management), perceivers consider characteristics that are originally gender specific to be normative of the prototype of the ideal manager. The gender-colored prototype of the ideal manager, in turn, serves as the standard for evaluating individuals (women or men) for or in managerial positions. In other words, the more male characteristics people project, the more they will select and positively evaluate a male candidate compared to a female candidate.

Principle 5: The extent to which one will project characteristics of their gender group onto an organization / position within an organization will determine their judgement of a potential applicant on a manager position. 
Our Gender Projection Model aims to account for both the recruiters (e.g., stereotypes and bias) and the candidates (e.g., vocational preferences) explanations of gender segregation in the workplace (Stockdale \& Nadler, 2012). We propose that the gender projection process will, on the one hand, accounts for discriminatory decisions from male recruiter with regards to female candidates, and, on the other hand, explain the motivation and intention (or lack thereof) of female prospective candidates to apply to such position, as well as the actual performance of women already occupying such positions.

Assumption 5.1: The more masculine traits (and/or less feminine traits) both men and women will project onto the manager prototype, the more they will select a male candidate over a female candidate for such a position.

Assumption 5.2: The more masculine traits (and/or less feminine traits) both men and women will project onto the manager prototype, the more positively they will evaluate the performance of a male manager.

And, conversely:

Assumption 5.3: The more masculine traits (and/or less feminine traits) both men and women will project onto the manager prototype, the less positively they will evaluate the performance of a female manager. 
The latter principle also accounts for the Backlash effect. As postulated by Rudman et al.'s (2012), the backlash effect is likely explained by the perception that an agentic female candidate poses a threat to the status quo. Such a backlash effect is usually characterized by the acknowledgement of the female candidate's competence associated with a decrease in likeability. Such reactions to the outgroup are usually generated by the perception that the outgroup threatens the ingroup in one way or another. At the heart of the social identity approach is the notion that people are motivated to achieve or maintain a social identity that is both positive and distinct. Group status and group distinctiveness are the main contextual factors that produce this threat (see Ellemers, Spears, \& Doosje, 2002). Therefore, one social identity may be perceived as threatened when it is impossible for the ingroup to achieve either a distinct or a positive identity. Threats to group distinctiveness may occur when the individual or the group is categorized in an unwanted higher-level group (i.e., categorization threat, see Branscombe, Ellemers, Spears, \& Doosje, 1999), or when the outgroup is perceived to be too similar to the ingroup (i.e., distinctiveness threat, see Gabarrot \& FalomirPichastor, 2017 ; Gabarrot, Falomir-Pichastor, \& Mugny, 2009 ; Jetten, Spears, \& Manstead, 1997 ; Spears, Doosje, \& Ellemers, 1997). Threat to group status may occur when the outgroup challenges the superior status of the ingroup, or when the ingroup is perceived as being of a lower status than the outgroup (see Branscombe et al., 1999). Hence, in the perspective of the gender projection model, the backlash effect could be perceived as a form of social identity threat eliciting more hostile reaction from the threatened group.

In addition to predicting the selection of a male or female candidate for a managerial position, as well as the performance evaluation of a male or female manager, we expect our model to also predict the self-selection and self-evaluation of men and women for such 
positions. Our model accounts for both aspiration of women to become manager and the actual performance deficit of women in leadership positions.

Principle 6: The extent to which one will project characteristics of their gender group onto an organization / position within an organization will determine their evaluation of their own ability or performance as a manager.

In particular, a reduced gender projection of women in leadership position can decrease women's performance and self-related cognitions in leadership tasks such as motivating employees, managerial decision-making, and negotiating. For instance, Bergeron, Block, and Echtenkamp (2006) found that the performance of women on a series of management-related task was impaired in a masculine sex-typed condition compared to a feminine sex-type condition (manipulated through a description of the participants' predecessor as being either male or female). However, their results showed that identification with the masculine gender role appeared to protect them against the negative effects of stereotype threat on women's performance. Similarly, Von Hippel, Issa, Ma and Stokes (2011) demonstrated that female employees who experienced stereotype threat were less confident that they would reach their career aspirations. This finding complements the results of Davies, Spencer, and Steele (2005) in which female university students disengaged from the leadership domain following stereotype threat. Several research examining gender stereotypes in managerial settings yielded similar results. For instance, in a leadership task such as influencing and motivating employees, stereotype threat led to decreased leadership performance for those female participants, in particular when they were low in self-efficacy (Hoyt \& Blascovich, 2010). Negotiation skills have also been shown to be affected by 
stereotype threat. When stereotypically feminine traits were linked to poor negotiation outcomes, women performed less well than men (Kray, Thompson, \& Galinsky, 2001). Women under stereotype threat adopted a masculine communication style, which in turn led to negative evaluations and less perceived managerial effectiveness (von Hippel, Wiryakusuma, Bowden, \& Shochet, 2011). Overall, these findings show that not only women feel threatened and discouraged when traditional gender stereotypes are activated, but their actual performance suffers from it.

Assumption 6.1: The more masculine traits (and/or less feminine traits) men will project onto the manager prototype, the more positive their evaluation of their own ability or performance as a manager will be, and the more likely they will be to apply to such positions.

Assumption 6.2: The more masculine traits (and/or less feminine traits) women will project onto the manager prototype, the less positive their evaluation of their own ability or performance as a manager will be, and the more likely they will be to apply to such positions.

In sum, we believe that the gender projection model is likely to capture a broad set of gender phenomena within organizations. The model has the capacity to make predictions not only from the point of view of the personnel decision-makers, but also from the point of view of the candidates, thus reconciling two families of explanations: the neoclassical economic approach, which emphasizes the self-selection of female candidates, and the more psychogical 
and sociological approaches, which generally highlight the social forces at play in this type of situation (Stockdale \& Nadler, 2012)

\section{Conclusion}

The GPM aims to complement existing theories on the under-representation of women in leadership positions. These theories are considering the cultural aspect and the pressure of society to remain consistent with its gender group, where those with power (usually men) prevent women from reaching high positions. The literature shows that men are associated with agentic characteristics and women with communal characteristics. The research proposes to associate these agentic and communal characteristics to a managerial position, and then to analyze which types of characteristics have been selected (our model allows us to study these questions with this methodology via our second equation). If the characteristics are agentic, it means that the position is associated with the group of men. However, this male-manager association is less strong on the women's side (see also Deal \& Stevenson, 1998; Dodge, Gilroy \& Fenzel, 1995; Martell \& DeSmet, 2001; Schein, Mueller \& Jacobson, 1989), or even non-existent (Brenner, Tomkiewicz \& Schein, 1989) and a man's preference for a leadership position disappears when both candidates (male and female) are presented as managers (Bosak \& Sczesny, 2011). Moreover, this "Think Male - Think Manager" association has decreased over time (Duehr \& Bono, 2006; Schein, 2007). Eagly \& Karau (2002) explains that women have a greater representation of the manager with female characteristics because they have more experience with a female manager than men. This argument, however, cannot explain the gender differences in the cognitive representation of the manager.

Our model proposes as an approach the projection of male and female characteristics to managerial positions. This approach is based on an individual vision of men and women 
and abstains from male-agency and female-community associations. In view of the evolution of our society, it seems important to us to focus on an individual representation - which translates into a projection - of this issue. In addition to allowing us to understand why men are still dominant in these managerial positions, our model allows a better adaptation to our societies and their evolution. For example, Cuddy, Wolf, Glick, Crotty, Chong and Norton (2015) examines the over-representation of men in managerial positions in South Korea. The authors show that this society requires men to possess agentic and communal characteristics. Traditional theories would not allow to put forward the male-manager association because communality is perceived as characteristics reserved for women. Nevertheless, the individual approach of our model offers the same predictions for individualistic (i.e., USA, Europe) as collectivist (i.e., Asia, Africa) societies. Finally, in addition to explaining gender differences in the prototype manager in general, our model also shows when such differences exist and when they do not (i.e., glass cliff phenomenon).

Our GPM, adding to other theories about cognitive representations of men and women (e.g., Eagly, 1987, Perry et al., 1994), offers theoretically grounded assumptions of when men and women differ in their manager prototypes. Understanding when-men as personnel decision makers may come to hold more masculine prototypes of managers than do women, is central for understanding the processes behind decisions about managerial and leadership positions because prototypes serve as benchmarks against which candidates are evaluated (e.g., Heilman, 1983, 1995; Eagly \& Karau, 2002). This contribution is not simply achieved by ascribing different social identity motives to men and women (e.g., men want to maintain the status of their gender group by ensuring that men are selected into prestigious positions), but by explaining the processes through which and also when these motives operate. Hence, we heed Reskin's (2003) call for “including mechanisms in our models of ascriptive inequality (p. 1)." GPM helps to explain the under-representation of women in leadership 
positions by linking theories that put women at the center of discrimination to sociological and psychosocial explanations that put men at the center of discrimination (see Stockdale \& Nadler, 2012). As an example of the added value of our model, consider that it implies that male (but not female) decision makers might be particularly motivated to have male-colored manager prototypes as the proportions of female candidates increases because increasing numbers of women pose a threat to male identities or threat the statu quo (Jost \& Banaji, 1994). In contrast, previous models would suggest that as more women are increasingly eligible as managers, the masculinity of manager prototypes held by men and also women should decrease due to new social realities. In addition to potential contributions to the literature on manager prototypes and ultimately female underrepresentation, our work might also add to research on ingroup projection by, among other things, theorizing and examining the impact of subordinate group stability and permeability on prototypes about superordinate groups as well as by proposing ingroup projection in cross cutting groups. 


\section{BIBLIOGRAPHY}

Abele, A. E., Ellemers, N., Fiske, S. T., Koch, A., \& Yzerbyt, V. (2020). Navigating the social world: Toward an integrated framework for evaluating self, individuals, and groups. Psychological Review. Advance online publication. doi:10.1037/rev0000262

Abrams, D., \& Hogg, M. A. 2004. Metatheory: Lessons from social identity research. Personality and Social Psychology Review, 8(2), 98-106.

Ashby, J.S., Ryan, M.K., \& Haslam, S.A. (2006). Legal work and the glass cliff: Evidence that women are preferentially selected to lead problematic cases. Wm \& Mary J. Women \& L., 13, 775 .

Atwater, L. E., Brett, J. F., Waldman, D., DiMare, L., \& Hayden, M. V. (2004). Men's and women's perceptions of the gender typing of management subroles. Sex Roles, 50(3), 191-199. doi: 10.1023/B:SERS.0000015551.78544.35

Bergeron, D. M., Block, C. J., \& Echtenkamp, A. (2006). Disabling the Able: Stereotype Threat and Women's Work Performance. Human Performance, 19(2), 133-158. doi:10.1207/s15327043hup1902_3

Bettencourt, B., Charlton, K., Dorr, N., \& Hume, D. L. (2001). Status differences and in group bias: a meta-analytic examination of the effects of status stability, status legitimacy, and group permeability. Psychological Bulletin, 127(4), 520.

Bongiorno, R., Bain, P. G., Ryan, M., Kroonenberg, P. M., \& Leach, C. W. (2021). Think leaders-think (Immoral, power-hungry) man: An expanded framework for understanding stereotype and leader gender bias [Preprint. PsyArXiv. https://doi.org/10.31234/osf.io/p5uya

Bosak, J., \& Sczesny, S. (2011). Gender bias in leader selection? Evidence from a hiring simulation study. Sex Roles, 65(3-4), 234-242. doi:10.1007/s11199-0110012-7

Branscombe, N. R., Ellemers, N., Spears, R., \& Doosje, B. (1999). The context and content of social identity threat. Social identity: Context, commitment, content, 35-58.

Brenner, O. c., Tomkiewicz, J., \& Schein, V. E. (1989). The relationship between sex role stereotypes and requisite management characteristics revisited. Academy of Management Journal, 32(3), 662-669. doi:10.5465/256439 
Bruckmüller, S., \& Branscombe, N. R. (2010). The glass cliff: When and why women are selected as leaders in crisis contexts. British Journal of Social Psychology, 49(3), 433451. doi:10.1348/014466609X466594

Burgess, D., \& Borgida, E. (1999). Who women are, who women should be: Descriptive and prescriptive gender stereotyping in sex discrimination. Psychology, Public Policy, and Law, 5(3), 665-692. doi:10.1037/1076-8971.5.3.665

Carli, L. L., \& Eagly, A. H. (1999). Gender effects on social influence and emergent leadership. In G. N. Powell (Ed.), Handbook of gender and work (p. 203-222). Sage Publications, Inc. doi:10.4135/9781452231365.n11

Catalyst (2010). Statistical overview of women in the workplace. Available online At http://catalyst.org/publication/219/statistical-overview-of-women-in-the-workplace

Cattonar, B. (2007). Les directeurs et les directrices d'école au Canada : Contexte, profil et travail. Enquêtes pancanadiennes auprès des directions et des enseignants d'écoles primaires et secondaires (2005-2006) [Report]. Chaire de recherche du Canada sur le personnel et les métiers de l'Éducation. Retrieved from https://depot.erudit.org/id/003041dd?mode=full\&locale=en

Cook, A., \& Glass, C. (2014). Women and top leadership positions: Towards an institutional analysis: women and leadership. Gender, Work \& Organization, 21(1), 91-103. doi:10.1111/gwao.12018

Coopersmith, J. (2009). Characteristics of public, private, and bureau of Indian education elementary and secondary school teachers in the United States: Results from the 200708 schools and staffing survey. First look. Nces 2009-324. National Center for Education Statistics. https://eric.ed.gov/?id=ED505837

Cuddy, A. J. C., Wolf, E. B., Glick, P., Crotty, S., Chong, J., \& Norton, M. I. (2015). Men as cultural ideals: Cultural values moderate gender stereotype content. Journal of Personality and Social Psychology, 109(4), 622-635. doi:10.1037/pspi0000027

Davies, P. G., Spencer, S. J., \& Steele, C. M. (2005). Clearing the Air: Identity Safety Moderates the Effects of Stereotype Threat on Women's Leadership Aspirations. Journal of Personality and Social Psychology, 88(2), 276-287. doi:10.1037/00223514.88.2.276 
Deal, J. J., \& Stevenson, M. A. (1998). Perceptions of female and male managers in the 1990s: Plus ça change . . . Sex Roles, 38(3), 287-300. doi:10.1023/A:1018741318216

Dodge, K. A., Gilroy, F. D., \& Fenzel, L. M. (1995). Requisite management characteristics revisited: Two decades later. Journal of Social Behavior and Personality, 10(4), $253-$ 264.

Duehr, E. E., \& Bono, J. E. (2006). Men, women, and managers: Are stereotypes finally changing? Personnel Psychology, 59(4), 815-846. doi:10.1111/j.17446570.2006.00055.x

Eagly, A. H. (1987). The interpretation of sex differences in social behavior: A social role interpretation. London: Lawrence Erlbaum Associates.

Eagly, A. H., \& Karau, S. J. (2002). Role congruity theory of prejudice toward female leaders. Psychological Review, 109(3), 573-598. doi:10.1037/0033-295X.109.3.573

Eagly, A. H., Makhijani, M. G., \& Klonsky, B. G. (1992). Gender and the evaluation of leaders: A meta-analysis. Psychological Bulletin, 111(1), 3-22. doi:10.1037/00332909.111.1.3

Eagly, A. H., Wood, W., \& Diekman, A. H. (2000). Social role theory of sex differences and similarities: A current appraisal. In T. Eckes \& H. M. Trautner (Eds.), The developmental social psychology of gender (pp. 123-174). Mahwah, NJ: Erlbaum

Ellemers, N., Spears, R., \& Doosje, B. (2002). Self and social identity. Annual Review of Psychology, 53(1), 161-186. doi:10.1146/annurev.psych.53.100901.135228

Ellemers, N., Rink, F., Derks, B., \& Ryan, M. K. (2012). Women in high places: When and why promoting women into top positions can harm them individually or as a group (And how to prevent this). Research in Organizational Behavior, 32, 163-187. https://doi.org/10.1016/j.riob.2012.10.003

Falomir-Pichastor, J. M., Gabarrot, F., \& Mugny, G. (2009). Group motives in threatening contexts: When a loyalty conflict paradoxically reduces the influence of an antidiscrimination ingroup norm. European Journal of Social Psychology, 39(2), 196-206.

Fiske, S. T., Cuddy, A. J. C., Glick, P., \& Xu, J. (2002). A model of (Often mixed) stereotype content: Competence and warmth respectively follow from perceived status and 
competition. Journal of Personality and Social Psychology, 82(6), 878-902. doi:10.1037/0022-3514.82.6.878

Fitzsimmons, T. W., Callan, V. J., \& Paulsen, N. (2014). Gender disparity int the C-suite: Do male and female CEOs differ in how they reached the top? The Leadership Quaterly, 25(2), 245-2656. doi: 10.1016/j.leaqua.2013.08.005

Gabarrot, F., \& Falomir-Pichastor, J. M. (2017). Ingroup identification increases differentiation in response to egalitarian ingroup norm under distinctiveness threat. International Review of Social Psychology, 30(1), 219-228. doi:10.5334/irsp.22

Gabarrot, F., Falomir-Pichastor, J. M., \& Mugny, G. (2009). Being similar versus being equal: Intergroup similarity moderates the influence of in-group norms on discrimination and prejudice. British Journal of Social Psychology, 48(2), 253-273. doi:10.1348/014466608X342943

Gaertner, S. L., \& Dovidio, J. F. (2000). The aversive form of racism. In C. Stangor (Ed.), Key readings in social psychology. Stereotypes and prejudice: Essential readings (p. 289304). Psychology Press.

Gartzia, L., Ryan, M. K., Balluerka, N., \& Aritzeta, A. (2012). Think crisis-think female: Further evidence. European Journal of Work and Organizational Psychology, 21(4), 603-628. doi:10.1080/1359432X.2011.591572

Glick, P., Fiske, S. T., Mladinic, A., Saiz, J. L., Abrams, D., Masser, B., ... \& Annetje, B. (2000). Beyond prejudice as simple antipathy: hostile and benevolent sexism across cultures. Journal of personality and social psychology, 79(5), 763.

Hains, S. C., Hogg, M. A., \& Duck, J. M. 1997. Self-categorization and leadership: Effects of group prototypicality and leader stereotypicality. Personality and Social Psychology Bulletin, 23(10), 1087-1100.

Haslam, S. A., \& Ryan, M. K. (2008). The road to the glass cliff: Differences in the perceived suitability of men and women for leadership positions in succeeding and failing organizations. The Leadership Quarterly, 19(5), 530-546. doi:10.1016/j.leaqua.2008.07.011 
Haut Conseil à l'Égalité entre les femmes et les hommes (2021). 10 ans de la loi CopéZimmerman 2011-2021. Available online https://www.haut-conseilegalite.gouv.fr/IMG/pdf/livret_-_10_ans_loi_cope-zimmermann.pdf

Heilman, M. E. (1983). Sex bias in work settings: The Lack of Fit model. Research in Organizational Behavior, 5, 269-298.

Heilman, M. E. (1995). Sex stereotypes and their effects in the workplace: What we know and what we don't know. Journal of Social Behavior and Personality, 10, 3-26.

Heilman, M. E. (2001). Description and prescription: How gender stereotypes prevent women's ascent up the organizational ladder. Journal of Social Issues, 57(4), 657-674. doi:10.1111/0022-4537.00234

Hogg, M. A., \& Abrams, D. 1988. Social identifications: A social psychology of intergroup relations and group processes. London: Routledge.

Hogg, M. A., \& Terry, D. J. 2001. Social identity processes in organizational contexts. Philadelphia, PA: Psychology Press.

Hoyt, C. L., \& Blascovich, J. (2010). The role of leadership self-efficacy and stereotype activation on cardiovascular, behavioral and self-report responses in the leadership domain. The Leadership Quarterly, 21, 89-103. doi: 10.1016/j.leaqua.2009.10.007

INSEE (2016). Introduction : analyser les inégalités salariales entre les hommes et les femmes dans la fonction publique avec les données du Système d'information sur les agents des services publics. Available online https://www.insee.fr/fr/statistiques/2123148?sommaire=2123156

Jetten, J., Spears, R., \& Manstead, A. S. R. (1997). Distinctiveness threat and prototypicality: combined effects on intergroup discrimination and collective self-esteem. European Journal of Social Psychology, 27(6), 635-657. doi:10.1002/(SICI)1099

Jost, J. T., \& Banaji, M. R. (1994). The role of stereotyping in system-justification and the production of false consciousness. British Journal of Social Psychology, 33(1), 1-27. doi:10.1111/j.2044-8309.1994.tb01008.x

Jost, J. T., Banaji, M. R., \& Nosek, B. A. (2004). A decade of system justification theory: Accumulated evidence of conscious and unconscious bolstering of the status quo. Political Psychology, 25(6), 881-919. doi:10.1111/j.1467-9221.2004.00402.x 
Kanter, R. M. (1977). Some effects of proportions on group life. In The gender gap in psychotherapy (pp. 53-78). Springer, Boston, MA.

Korn Ferry (2016). Gender Pay Analysis: Technical Methodology and data report. Available online http://info.haygroupupdate.com/rs/494-VUC482/images/KFHG_Gender\%20pay\%20Gap_Technical\%20report.pdf

Koenig, A.M., Eagly, A.H., Mitchell, A.A., \& Ristikari, T. (2011). Are leaders stereotypes masculine? A meta-analysis of three research paradgimes. Psychological bulletin, $137(4), 616$.

Kray, L. J., Thompson, L., \& Galinsky, A. (2001). Battle of the sexes: Gender stereotype confirmation and reactance in negotiations. Journal of Personality and Social Psychology, 80, 942-958. doi: 10.1037/0022-3514.80.6.942

Le Monde (2019). A partir du 5 novembre à 16 h 47, les Françaises travailleront pour rien. Available online https://www.lemonde.fr/economie/article/2019/11/03/salaires-a-partirdu-5-novembre-16h47-les-francaises-travailleront-pour-rien_6017895_3234.html

Le Monde (2020). Anne Boring : « Pourquoi les filles sont-elles moins payées que les garçons ?». Available online https://www.lemonde.fr/idees/article/2020/07/17/anneboring-pourquoi-les-filles-sont-elles-moins-payees-que-lesgarcons_6046517_3232.html

Luhtanen, R., \& Crocker, J. (1992). A collective self-esteem scale: Self-evaluation of one's social identity. Personality and Social Psychology Bulletin, 18(3), 302-318. doi:10.1177/0146167292183006

Lyness, K. S., \& Heilman, M. E. (2006). When fit is fundamental: Performance evaluations and promotions of upper-level female and male managers. Journal of Applied Psychology, 91(4), 777-785. doi:10.1037/0021-9010.91.4.777

Magee, J. C., \& Galinsky, A. D. (2008). 8 social hierarchy: The self-reinforcing nature of power and status. Academy of Management Annals, 2(1), 351-398. doi:10.5465/19416520802211628

Martell, R. F., \& DeSmet, A. L. (2001). A diagnostic-ratio approach to measuring beliefs about the leadership abilities of male and female managers. Journal of Applied Psychology, 86(6), 1223-1231. doi:10.1037/0021-9010.86.6.1223 
Morgenroth, T., Kirby, T. A., Ryan, M. K., \& Sudkämper, A. (2020). The who, when and why of the glass cliff phenomenon: A meta-analysis of appointments to precarious leadership positions. Psychological bulletin, 146(9), 797.

Morrison, A. M., \& Von Glinow, M. A. (1990). Women and minorities in management. American Psychologist, 45(2), 200-208. doi:10.1037/0003-066X.45.2.200

Nauts, S. (2015). Backlash for gender atypicality (Doctoral dissertation, Radboud University, Nijmegen, Netherlands). Retrieved from https://repository.ubn.ru.nl/bitstream/handle/2066/143201/143201.pdf

Oakes, P. J., Haslam, S. A., \& Turner, J. C. 1998. The role of prototypicality in group influence and cohesion: Contextual variation in the graded structure of social categories. In S. Worchel \& J. F. Morales (Eds.), Social identity: International perspectives: 75-92. London, UK: Sage.

OECD (2017). «L'égalité femmes-hommes dans l'OCDE et à travers le monde : une vue d'ensemble », in Atteindre l'égalité femmes-hommes : un combat difficile, Editions OCDE, Paris, https://doi.org/10.1787/9789264203426-4-fr.

Perry, E. (1994). A prototype matching approach to understanding the role of applicant gender and age in the evaluation of job applicants. Journal of Applied Social Psychology, 24, 1433-1473. doi:10.1111/j.1559-1816.1994.tb01558.x

Perry, E. L., Davis-Blake, A., \& Kulik, C. T. (1994). Explaining gender-based selection decisions: A synthesis of contextual and cognitive approaches. The Academy of Management Review, 19(4), 786. doi:10.2307/258745

Postmes, T., Baray, G., Haslam, S. A., Morton, T., \& Swaab, R. 2006. The dynamics of personal and social identity formation. In T. Postmes \& J. Jetten (Eds.), Individuality and the group: Advances in social identity, 215-236. London, UK: Sage.

Powers, T. A., \& Zuroff, D. C. (1988). Interpersonal consequences of overt self-criticism: A comparison with neutral and self-enhancing presentations of self. Journal of Personality and Social Psychology, 54(6), 1054-1062. doi:10.1037/0022-3514.54.6.1054

Pratto, F., Sidanius, J., Stallworth, L. M., \& Malle, B. F. (1994). Social dominance orientation: A personality variable predicting social and political attitudes. Journal of Personality and Social Psychology, 67(4), 741-763. doi:10.1037/0022-3514.67.4.741 
Reicher, S., \& Hopkins, N. (2001). Psychology and the end of history: a critique and a proposal for the psychology of social categorisation. Political Psychology, 22(2), 383407.

Reskin, B. F. (2003). Including mechanisms in our models of ascriptive inequality: 2002 presidential address. American Sociological Review, 68(1), 1. doi:10.2307/3088900

Ridgeway, C. L. (2009). Framed before we know it: How gender shapes social relations. Gender \& society, 23(2), 145-160.

Rudman, L. A. (1998). Self-promotion as a risk factor for women: The costs and benefits of counterstereotypical impression management. Journal of Personality and Social Psychology, 74(3), 629-645. doi:10.1037/0022-3514.74.3.629

Rudman, L. A., \& Fairchild, K. (2004). Reactions to couterstereotypic behavior: the role of backlash in cultural stereotype maintenance. Journal of personality and social psychology, 87(2), 157.

Rudman, L. A., \& Glick, P. (1999). Feminized management and backlash toward agentic women: The hidden costs to women of a kinder, gentler image of middle managers. Journal of Personality and Social Psychology, 77(5), 1004-1010. doi:10.1037/00223514.77.5.1004

Rudman, L. A., \& Glick, P. (2001). Prescriptive gender stereotypes and backlash toward agentic women. Journal of Social Issues, 57(4), 743-762. doi:10.1111/0022-4537.00239

Rudman, L. A., \& Kilianski, S. E. (2000). Implicit and explicit attitudes toward female authority. Personality and Social Psychology Bulletin, 26(11), 1315-1328. doi:10.1177/0146167200263001

Rudman, L. A., Moss-Racusin, C. A., Glick, P., \& Phelan, J. E. (2012). Reactions to vanguards: Advances in backlash theory. In P. Devine \& A. Plant (Eds.), Advances in Experimental Social Psychology (Vol. 45, p. 167-227). Academic Press. doi:10.1016/B978-0-12-394286-9.00004-4

Rudman, L. A., Moss-Racusin, C. A., Phelan, J. E., \& Nauts, S. (2012). Status incongruity and backlash effects: Defending the gender hierarchy motivates prejudice against female leaders. Journal of Experimental Social Psychology, 48(1), 165-179. doi:10.1016/j.jesp.2011.10.008 
Rudman, L. A., \& Phelan, J. E. (2008). Backlash effects for disconfirming gender stereotypes in organizations. Research in Organizational Behavior, 28, 61-79. doi:10.1016/j.riob.2008.04.003

Ryan, M. K., \& Haslam, S. A. (2005). The glass cliff: Evidence that women are over represented in precarious leadership positions. British Journal of Management, 16(2), 81-90. doi:10.1111/j.1467-8551.2005.00433.x

Ryan, M. K., \& Haslam, S. A. (2007). The glass cliff: Exploring the dynamics surrounding the appointment of women to precarious leadership positions. Academy of Management Review, 32(2), 549-572. doi:10.5465/amr.2007.24351856

Ryan, M. K., \& Haslam, S. A. (2008). The road to the glass cliff: Differences in the perceived suitability of men and women for leadership positions in succeeding and failing organizations. The Leadership Quaterly, 19(5), 530-546.

Ryan, M. K., Haslam, S. A., Hersby, M. D., \& Bongiorno, R. (2011). Think crisis-think female: The glass cliff and contextual variation in the think manager-think male stereotype. Journal of Applied Psychology, 96(3), 470-484. doi:10.1037/a0022133

Ryan, M. K., Haslam, S. A., Morgenroth, T., Rink, F., Stoker, J., \& Peters, K. (2016). Getting on top of the glass cliff: Reviewing a decade of evidence, explanations, and impact. The Leadership Quarterly, 27(3), 446-455. doi:10.1016/j.leaqua.2015.10.008

Ryan, M. K., Haslam, S.A., \& Postmes, T. (2007). Reactions to the glass cliff: Gender differences in the explanations for the precariousness of women's leadership positions. Journal of Organizational Change Management, 20(2), 182-197. doi:10.1108/09534810710724748

Spears, R., Doosje, B., \& Ellemers, N. (1997). Self-stereotyping in the face of threats to group status and distinctiveness: The role of group identification. Personality and Social Psychology Bulletin, 23(5), 538-553. doi:10.1177/0146167297235009

Schein, V. E. (1973). The relationship between sex role stereotypes and requisite management characteristics. Journal of Applied Psychology, 57(2), 95-100. doi:10.1037/h0037128

Schein, V. E. (1975). Relationships between sex role stereotypes and requisite management characteristics among female managers. Journal of Applied Psychology, 60(3), 340-344. doi:10.1037/h0076637 
Schein, V. E. (2001). A global look at psychological barriers to women's progress in management. Journal of Social Issues, 57(4), 675-688. doi:10.1111/0022-4537.00235

Schein, V. E. (2007). Women in management: Reflections and projections. Women in Management Review, 22(1), 6-18. doi:10.1108/09649420710726193

Schein, V. E., Mueller, R., \& Jacobson, C. (1989). The relationship between sex role stereotypes and requisite management characteristics among college students. Sex Roles, 20(1), 103-110. doi:10.1007/BF00288030

Sidanius, J., \& Pratto, F. (2001). Social dominance: An intergroup theory of social hierarchy and oppression (1. paperback ed). Cambridge Univ. Press.

Spears, R., Doosje, B., \& Ellemers, N. (1997). Self-stereotyping in the face of threats to group status and distinctiveness: The role of group identification. Personality and social psychology bulletin, 23(5), 538-553.

Stockdale, M. S., \& Nadler, J. T. (2012). Paradigmatic assumptions of disciplinary research on gender disparities: The case of occupational sex segregation. Sex Roles, 68(3-4), 207-215. doi:10.1007/s11199-012-0228-1

Tajfel, H., \& Turner, J. C. (1986). The social identity theory of intergroup behavior. In S. Worchel \& W. Austin (Eds.). Psychology of intergroup relations (pp. 7-24). Chicago: Nelson-Hall.

Tower et al. 1987

Turner, J. C., \& Haslam, S. A. 2001. Social identity, organizations and leadership. In M. E. Turner (Ed.), Groups at work: Advances in theory and research, 25-65.

Turner, J. C., Hogg, M. A., Oakes, P. J., Reicher, S. D., \& Wetherell, M. S. (1987). Rediscovering the social group: A self-categorization theory. Basil Blackwell.

Turner, J. C., Reynolds, K. J., Haslam, S. A., \& Veenstra, K. 2006. Reconceptualizing personality: Producing individuality through defining the personal self. In T. Postmes \& J. Jetten (Eds.), Individuality and the group: Advances in Social Identity:1-36. London, UK: Sage.

Van Knippenberg, D. (2000). Work motivation and performance: A social identity perspective. Applied Psychology: An International Review, 49(3), 357-371. 
Van Knippenberg, D., \& Hogg, M. A. (2003). A social identity model of leadership effectiveness in organizations. Research in Organizational Behavior, 25, 243-295.

Von Hippel, C., Issa, M., Ma, R., \& Stokes, A. (2011). Stereotype threat: Antecedents and consequences for working women. European Journal of Social Psychology, 41(2), 151161. doi:10.1002/ejsp.749

Von Hippel, C., Wiryakusuma, C., Browden, J., \& Shochet, M. (2011). Stereotype threat and female communication styles. Personality and Social Psychology Bulletin, 37(10, 13121324.

Waldzus, S., Mummendey, A., Wenzel, M., \& Boettcher, F. (2004). Of bikers, teachers and Germans: Groups' diverging views about their prototypicality. British Journal of Social Psychology, 43(3), 385-400.

Watkins, M.B., Simmons, A., \& Umphress, E. (2019). It's not black and white: Toward a contingency perspective on the consequences of being a token. Academy of Management Perspectives, 33(3), 334-365.

Wenzel, M., Mummendey, A., \& Waldzus, S. (2007). Superordinate identities and intergroup conflict: The ingroup projection model. European Review of Social Psychology, 18(1), 331-372. Doi: 10.1080/10463280701728302

Wenzel, M., Mummendey, A., Weber, U., \& Waldzus, S. (2003). The ingroup as pars pro toto: Projection from the ingroup onto the inclusive category as a precursor to social discrimination. Personality and Social Psychology Bulletin, 29(4), 461-473. doi:10.1177/0146167202250913

Williams, C. L. (1992). The glass escalator: Hidden advantages for men in the "female" professions. Social Problems, 39(3), 253-267. doi:10.2307/3096961

Wood, W., \& Eagly, A. H. (2010). Gender. In S. T. Fiske, D. T. Gilbert, \& G. Lindzey (Eds.), Handbook of social psychology (p. 629-667). John Wiley \& Sons, Inc. doi:10.1002/9780470561119.socpsy001017

Wood, W., \& Eagly, A. H. (2012). Chapter two-Biosocial construction of sex differences and similarities in behavior. In J. M. Olson \& M. P. Zanna (Eds.), Advances in Experimental Social Psychology, 46, 55-123. Academic Press. doi:10.1016/B978-0-12394281-4.00002-7 
Wood, W. \& Eagly, A. H. (2015). Two traditions of research on gender identity. Sex Roles, 73(11), 461-473.

Yoder, J. D. (1991). Rethinking tokenism: Looking beyond numbers. Gender \& Society, 5(2), 178-192. doi:10.1177/089124391005002003 


\section{Footnotes}

1. It is important to note that although the studies and meta-analysis cited above reveal a gender difference in the glass ceiling phenomenon, a more recent meta-analysis focusing more on the glass cliff phenomenon fails to show such a difference (Morgenroth et al., 2020). This could be explained by the fact that women may see these glass cliff situations as an opportunity for change and as a way to move into positions they have not previously been able to access. The precarious situation of women in organizations would make them prefer a position of responsibility even when it represents a high risk of failure than no position at all. Another possibility would be that women would adhere to the rhetoric of change put forward by the dominant group, even if the latter's deep motivations are not as noble as they might seem.

2. Theoretically, such permeability would induce a strategy of individual mobility. Such strategy implies that women aiming for this type of position should engage in a social projection rather than gender projection (i.e. project their individual characteristics, rather than gender-specific characteristics, onto the manager position). However, (a) these individual characteristics are likely to be very similar to their gender characteristics, especially if these women strongly identify with their gender, and (b) the distinction between gender projection and social projection is beyond the scope of this article, but will be the object of future empirical research. 


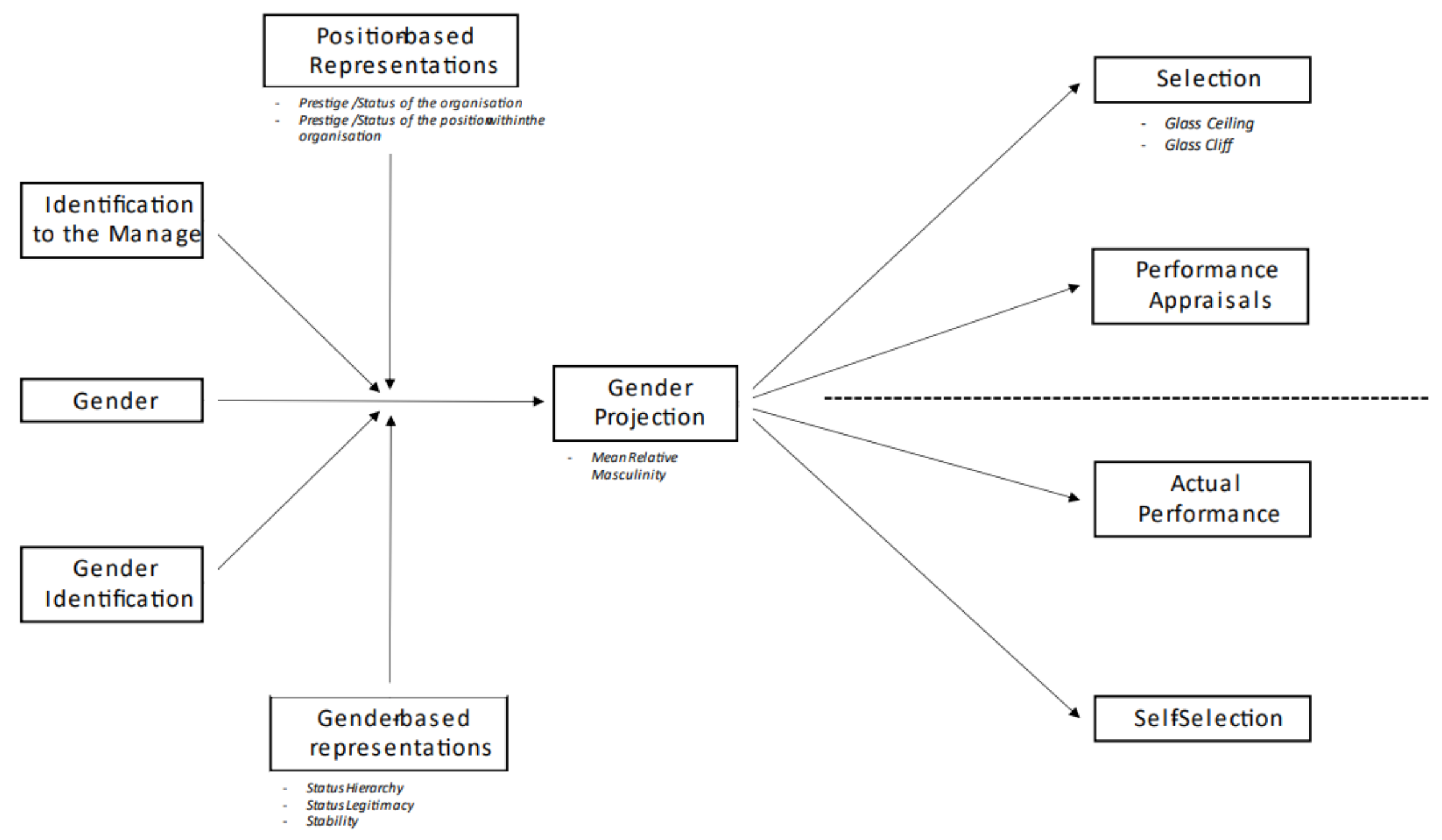

